\title{
RANCANG BANGUN SISTEM INFORMASI SURAT MENYURAT BERBASIS WEB PADA PT. RADAR RIAU
}

\section{DESIGN OF WEB-BASED LETTER INFORMATION SYSTEM AT PT RADAR RIAU}

\author{
Muhammad Luthfi Hamzah, *Mochammad Adhitya Pabottingi, Eki Saputra, \\ Anofrizen, Sutoyo \\ Universitas Islam Negeri Sultan Syarif Kasim Riau \\ 11850312402@students.uin-suska.ac.id*
}

\begin{abstract}
PT. Radar Riau is a private agency engaged in the press media. Some of the problems that occur are at the end of the month / year some letter archive data will be collected, employees must be busy looking for data first and also ask other employees to find the letter archive they want to search. To solve this problem, a correspondence administration information system is needed that can facilitate the process of numbering and filing letters, existing mail data and monthly reports of incoming or outgoing mail using this information system. The analysis and system design stages use the Object Oriented Analysis Design $(O O A D)$ technique, the system development method uses the waterfall method and the system design uses the Unified Modelling Language (UML) diagram. The end result of this research is in the form of an information system design that can provide facilities for agencies in the administrative service process in order to meet the needs of PT. Radar Riau in terms of numbering and filing letters.
\end{abstract}

Keywords: Unified Modelling Language, Object Oriented Analysis Design, Waterfall.

\begin{abstract}
ABSTRAK
PT. Radar Riau merupakan sebuah Instansi swasta yang bergerak di bidang media pers. Beberapa masalah yang terjadi adalah saat akhir bulan/tahun beberapa data arsip surat akan di kumpulkan, pegawai harus sibuk mencari data terlebih dahulu dan juga bertanya pegawai lain untuk mencari arsip surat yang ingin di cari. Untuk mengatasi masalah tersebut dibutuhkan sistem informasi administrasi surat- menyurat yang dapat memberi kemudahan dalam proses penomoran dan pengarsipan surat, data surat yang ada serta laporan bulanan surat masuk atau keluar dengan menggunakan sistem informasi tersebut. Tahapan analisa dan perancangan sistem menggunakan teknik Object Oriented Analysis Design (OOAD) metode pengembangan sistem menggunakan metode waterfall dan perancangan sistem menggunakan diagram Unified Modeling Language (UML). Hasil akhir dari penelitian ini berupa sebuah rancang bangun sistem informasi yang dapat memberi kemudahan bagi instansi dalam proses pelayanan administrasi agar dapat memenuhi kebutuhan PT. Radar Riau dalam hal penomoran dan pengarsipan surat.
\end{abstract}

Kata Kunci: Unified Modeling Language, Object Oriented Analysis Design, waterfall

\section{PENDAHULUAN}

Pesan ialah perlengkapan komunikasi yang berarti dalam suatu lembaga. Tiap pesan masuk yang diterima serta pesan keluar yang dikirim oleh sesuatu lembaga, tidak cuma hanya selaku perlengkapan komunikasi namun pula selaku fakta autentik (Susanto, et. al., 2021). Perihal ini sekalian bisa menampilkan dinamika ataupun aktivitas hidup sesuatu kantor ataupun organisasi. Oleh sebab itu pengelolaan ataupun penindakan pesan masuk serta pesan keluar wajib dicoba setepattepatnya sehingga senantiasa bisa diiringi proses perkembangannya. pesan merupakan sehelai kertas ataupun lebih yang digunakan buat mengadakan komunikasi secara tertulis (Atmala, A. R., \& Ramadhani, S., 2020).

Tiap lembaga pemerintah bisa ditentukan memiliki sesuatu unit spesial yang bertugas dalam bidang administrasi. Dengan kata lain tiap lembaga pemerintah tentu membutuhkan sesuatu unit yang 
mengelola seluruh suatu yang berhubungan dengan aktivitas administrasi yang pada kesimpulannya hendak berhubungan dengan aktivitas kearsipan semacam pengarsipan pesan masuk serta pesan keluar. Meningkatnya jumlah pesan masuk serta pesan keluar dari tahun ke tahun membuat pengelolaan pesan masuk serta pesan keluar jadi bertambah pula, sebaliknya sepanjang ini proses pengelolaan pesan masuk serta pesan keluar dicoba secara manual(Farell, et. al., 2018).

Salah satu pelaksanaan teknologi data yang berarti di lembaga pemerintahan merupakan sistem kearsipan. Perihal ini disebabkan sistem kearsipan berperan selaku memori kolektif lembaga(corporate memory), media informasi ataupun data untuk pengambilan keputusan(decisions making), bahan pendukung proses majelis hukum(litigation support) serta penyusutan berkas kerja(retention) (Nozomi, I., \& Hamzah, M., 2018; Asyari, M. R., 2021).

PT. Radar Riau merupakan instansi swasta yang bergerak dibidang media pers dan juga bergerak dibidang berita online serta percetakan koran. Dalam melakukan tugasnya, kantor ini banyak terlibat dalam surat menyurat. Bagian yang menangani surat menyurat ini adalah bagian umum.

Dari proses pengelolaan pesan masuk serta pesan keluar yang semacam ini memunculkan sebagian permasalahan antara lain merupakan dengan terus menjadi banyaknya pesan masuk serta pesan keluar menyebabkan terbentuknya penimbunan catatan serta penimbunan arsip, perihal ini pula hendak membuat kesusahan dalam proses pencarian data- data pesan yang telah lama bertitik tolak dari pemaparan di atas, hingga pengembangan sistem data ini bertujuan buat tingkatkan efisiensi, ketepatan serta keamanan dokumen yang diarsipkan (Oktaviani, E., \& Noviana, S. , 2020). Diharapkan dengan adanya sistem informasi pengarsipan ini, dapat merubah sistem kinerja tata usaha dalam proses pengarsipan surat masuk dan surat keluar menjadi lebih efektif dan efisien(Mayasari, et. al., 2020).

Hasil observasi awal yang dilakukan terdapat beberapa kendala dalam pengelolaan surat masuk, seperti: (1) tidak semua surat terarsipkan dengan baik; (2) kesalahan pencatatan nomor surat; (3) kesalahan pembuatan alamat tujuan disposisi; dan (4) hilangnya surat. Kendala-kendala tersebut disebabkan oleh beberapa hal, yaitu: (1) banyaknya jumlah surat masuk dan surat keluar (tahun 2018 sampai 2020 tercatat ada 665 surat masuk dan 565 surat keluar); (2) tidak semua surat diserahkan pada petugas pengelola surat tetapi masih disimpan di masing-masing bidang yang berkepentingan atau tujuan dari surat tersebut; (3) pegawai yang meminjam surat tidak mengembalikan pada petugas pengelola surat; dan (4) ada banyak (sembilan buah) tujuan disposisi surat(Setiawan, et. al., 2020). Berdasarkan latar belakang yang telah dijelaskan, maka studi ini membuat sistem informasi pengarsipan surat di PT. Radar Riau, Kota Pekanbaru Provinsi Riau untuk mengatasi permasalahan yang terjadi.

Diharapkan dengan adanya sistem ini dapat mengurangi penggunaan waktu yang cukup lama dalam pengarsipan surat, memperkecil terjadinya kesalahan dalam pencatatan surat, mempercepat proses pencarian surat, memperkecil terjadinya kehilangan surat, serta memudahkan mengontrol disposisi surat(Sihotang, H. T., 2018).

Agar sistem informasi yang dibuat tidak menyimpang dari permasalahan 
yang ada, maka perlu dibuat suatu pembatasan ruang lingkupnya. Adapun ruang lingkup dalam sistem informasi antara lain:

1. Merancang sistem informasi pengarsipan surat yang meliputi surat masuk, dan surat keluar .

2. Menggunakan model rekayasa SDLC (Sistem Development Life Cycle) Waterfall sebagai metode pengembangan system nya yang menggunakan 4 tahap dari model Waterfall ini dimulai dari Analisis, Desain, Pengkodingan, Pengujian.

3. Sistem informasi ini dirancang dengan metode OOAD dan menggunakan 4 diagram Unified Modelling Languange (UML) yaitu Use Case Diagram, Class Diagram, Activity Diagram, Sequence Diagram.

4. Sistem ini dibangun berbasis web dan menggunakan bahasa PHP serta menggunakan database MySQL.

5. Sistem informasi ini di rancang untuk pegawai instansi sebagai user, dan kepala instansi sebagai admin.

Object Oriented Analysis (OOA) adalah tahapan untuk menganalis spesifikasi atau kebutuhan akan sistem yang akan dibangun dengan konsep berorientasi objek, apakah benar kebutuhan yang dapat diimplementasikan menjadi sebuah sistem berorientasi objek. Biasanya analisa sistem dimulai dengan adanya dokumen permintaan (requirement) yang diperoleh dari semua pihak yang berkepentingan.

Object Oriented Design (OOD) adalah merancang kelas-kelas yang terindetifikasi selama tahap analisi dan antarmuka (user interface). Selama tahap ini kita menidentifikasi dan menambah beberapa objek dan kelas yang mendukung implementasi dari spesifikasi kebutuhan.

OOA dan OOD dalam proses yang berulang-ulang seringnya memiliki batasan yang samar, sehingga kedua tahapan ini sering juga disebut Object Oriented Analysis and Design (OOAD).

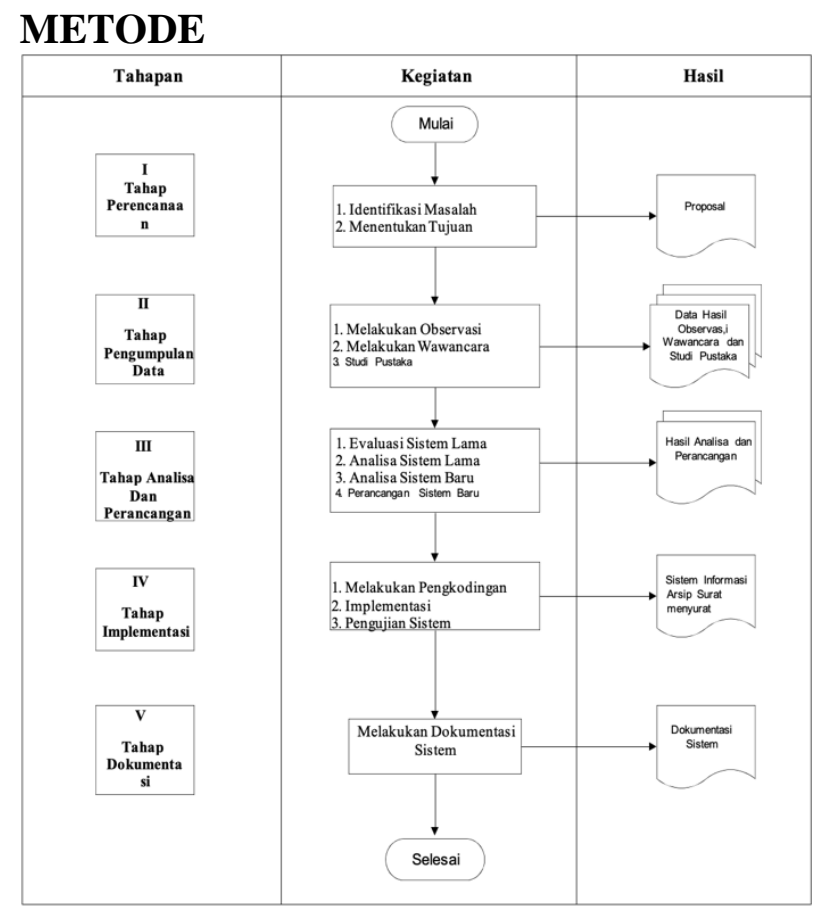

Gambar 1. Alur Penelitian

a. Tahap Perencanaan

Tahap Perencanaan ini adalah tahap awal di mana penelitian akan dilaksanakan dan juga akan mengetahui permasalahan perusahaan yang sering terjadi dan dapat mengatasinya.

1. Mengindentifikasi Permasalahan yang sering terjadi di Kantor PT. Radar Riau

2. Menentukan tujuan berjalannya progres untuk menjadi tahapan penelitian ini.

b. Tahap Pengumpulan Data

Pada tahapan ini adalah proses di mana kita mengumpulkan data dari awal sampai selesainya kegiatan penelitian tersebut.

1. Observasi

Observasi ini bertujuan meneliti apa yang sedang berjalan di 
Kantor Harian Umum Radar Riau, dan juga tujuannya untuk mengetahui Visi, Misi kantor tersebut.

2. Wawancara

Wawancara tersebut tujuannya adalah mewawancarai Pihak Pimpinan Redaksi dan kepegawaian agar mengetahui permasalahan yang sedang berjalan di instansi dan segera mencari solusinya agar bisa memperbaiki permasalahan tersebut.

c. Tahap Analisa Dan Hasil

Pada tahapan ini setelah observasi perancangan kita bisa menentukan sistem yang akan dibutuhkan oleh Kantor Harian Umum Radar Riau.

1. Menganalisa sistem lama yang sedang berjalan di Kantor Harian Umum Radar Riau Masih menggunakan sistem manual dengan menggunakan buku besar sebagai pencatatan arsip surat masuk dan surat keluar.

2. Pengusulan sistem yang akan di berikan kepada instansi adalah sistem informasi pengelolaan surat tujuannya adalah mempermudah Pimpinan Redaksi dan kepegawaian dan bagian pelayanan dalam bagian surat untuk melakukan pengolahan surat masuk dan surat keluar.

3. Merancang sekaligus mendesain database sistem pengelolaan surat yang akan digunakan pada , dengan terlebih dahulu melakukan analisa terhadap field dan entitas apa saja yang akan diperlukan.

4. Membuat Interface System pengelolaan surat yang akan digunakan pada Kantor Harian Umum Radar Riau. d. Tahap Implementasi

Pada tahapan ini setelah melakukan perancangan database dan interface system kita selanjutnya melakukan implementasi sistem yang akan di gunakan pada Kantor Harian Umum Radar Riau.

1. Menginstal sistem pengelolaan surat yang telah dibuat sebelumnya pada tahap perancangan.

2. Melakukan training penggunaan sistem pada pegawai pelayanan, Pimpinan Redaksi dan kepegawaian.

e. Tahap Dokumentasi

Pada tahap pembuatan dokumentasi final sistem yang dibangun.

\section{HASIL DAN PEMBAHASAN Analisa Sistem}

Analisa sistem didefenisikan sebagai penguraian suatu sistem informasi yang utuh kedalam komponen-komponen yang bertujuan untuk mengidentifikasi, mengetahui dan memahami serta melakukan proses evaluasi yang baik atas permasalahan yang terjadi. Kegiatan analisa sistem dilakukan untuk mendapatkan gambaran secara jelas tentang bentuk permasalahan yang ada pada intansi tersebut. Sehingga mengurangi kesalah pahaman antara sistem analis dengan user. Setelah gambaran sistem didapatkan maka akan diuraikan bagaimana perencanaan sistem usulan yang diharapkan memenuhi kebutuhan para pengguna sistem(Wisudya, R. Y., \& Putra, W. M., 2020).

Analisa Sistem yang Sedang Berjalan

Sistem yang sedang berjalan di PT. Radar Riau masih menggunakan proses manual yaitu: 1) pegawai yang akan melampirkan nomor pada surat yang masuk pada PT. Radar Riau 2) pegawai menyerahkan surat kepada pimpinan umump yang sedang bertugas 3) pimpinan menanyakan apakah surat ini 
sudah ada salinan untuk disimpa sebagai arsip 4) jika belum ada salinan maka pimpinan akan menyuruh menyalin nya langsung 5) jika ada salinan pegawai akan langsung menyerahkan kepada pimpinan 6) pimpinan mencatat dan memberi nomor pada surat.

\section{Rencana Sistem Usulan}

Sistem informasi yang diusulkan memiliki beberapa keunggulan dari sistem yang sedang berjalan. Adapun gambaran dari sistem yang diusulkan ialah, sistem telah terkomputerisasi, lebih mudah digunakan, keamanan data terjaga, mempermudah dan mempercepat dalam pembuatan laporan dan pengarsipan surat masuk dan surat keluar. Dan terdapat pencetakan laporan pengarsipan surat dan bisa dikontrol oleh Bagian staf perusahaan.

Pada tahap perancangan sistem ini akan memberi gambaran mengenai sistem usulan serta menjelaskan tentang rancangan kerja sistem yang diusulkan. Deskripsi sistem yang diusulkan menggunakan diagram UML(Hamzah, et. al., 2019).

\section{Use Case Diagram}

Diagram Use case menyajikan interaksi antara use case dan actor. Dimana actor dapat berupa orang, peralatan, atau sistem lain yang berinteraksi dengan sistem yang sedang dibangun. Use case menggambarkan fungsionalitas sistem atau persyaratanpersyaratan yang harus dipenuhi sistem dari pandangan pemakai atau pengguna.

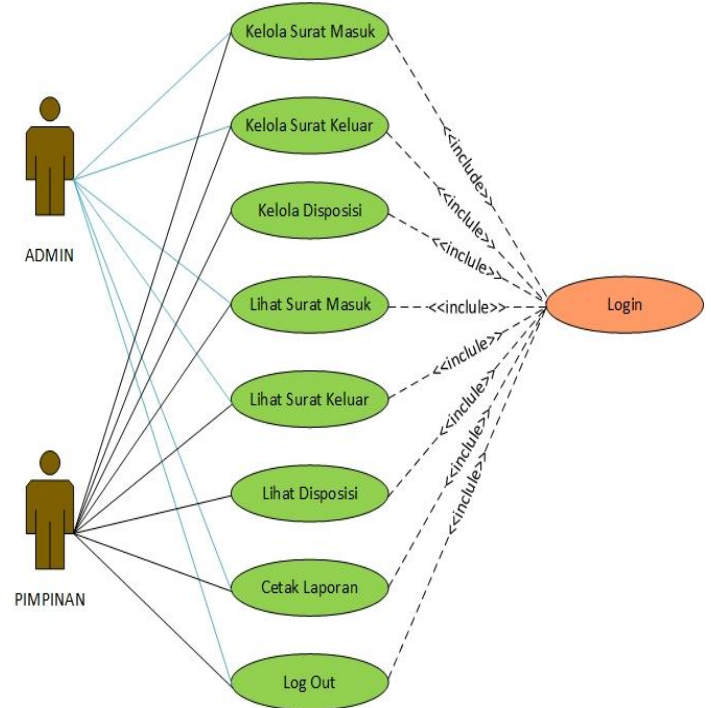

Gambar 2. Use Case Diagram

Deskripsi Use Case Diagram

Berikut ini merupakan deskripsi dari masing-masing use case yang berada pada sistem informasi Pengarsipan Surat PT. Radar Riau, yaitu terlihat pada tabel 1.

Table 1. Deskripsi Use Case

\begin{tabular}{ccl}
\hline 1 & Login & $\begin{array}{l}\text { Use case ini menggambarkan } \\
\text { user masuk ke dalam sistem. }\end{array}$ \\
\hline 2 & Surat Masuk & $\begin{array}{l}\text { Use case ini menggambarkan } \\
\text { kegiatan dalam melakukan } \\
\text { penginputan data surat } \\
\text { masuk. }\end{array}$ \\
\hline 3 & Surat Keluar & $\begin{array}{l}\text { Use case ini menggambarkan } \\
\text { kegiatan dalam melakukan } \\
\text { penginputan data surat keluar. }\end{array}$ \\
\hline 4 & Disposisi Surat & $\begin{array}{l}\text { Use case ini menggambarkan } \\
\text { Pimpinan umum sebagai } \\
\text { admin melakukan proses } \\
\text { kelola data disposisi. }\end{array}$ \\
\hline 5 & Lihat Laporan & $\begin{array}{l}\text { Use case ini untuk melihat } \\
\text { laporan arsip yang telah di- } \\
\text { input } \text { oleh admin. }\end{array}$ \\
\hline 6 & Cetak Laporan & $\begin{array}{l}\text { Use case ini mengambarkan } \\
\text { pencetakan laporan yang } \\
\text { dilakukan oleh admin. }\end{array}$ \\
\hline 7 & Logout & $\begin{array}{l}\text { Use case ini untuk user keluar } \\
\text { dari sistem. }\end{array}$ \\
\hline
\end{tabular}

\section{Hasil}

Berdasarkan hasil analisa dan rancangan yang dilakukan sebelumnya maka dihasilkanlah sebuah sistem informasi pengarsipan surat masuk dan surat keluar pada PT. Radar Riau. Jumlah 
halaman web yang terdapat pada sistem ini adalah 11 halaman. Berikut ini adalah screenshoot dari hasil sistem pengarsipan surat yang telah dibangun.

\section{Halaman Login}

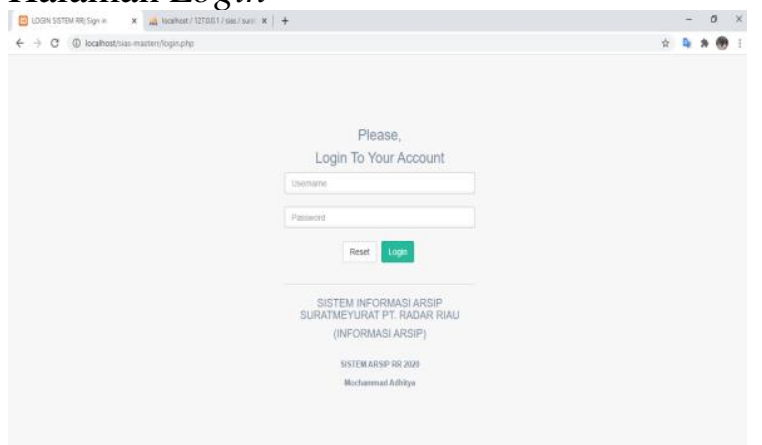

Gambar 3. Halaman Login

Halaman Login merupakan tampilan pertama saat menjalankan sistem dan juga merupakan tampilan halaman Login untuk admin. Sebelum masuk kehalaman utama sistem admin diminta untuk memasukkan username dan password agar bisa Login.

Halaman Menu Utama

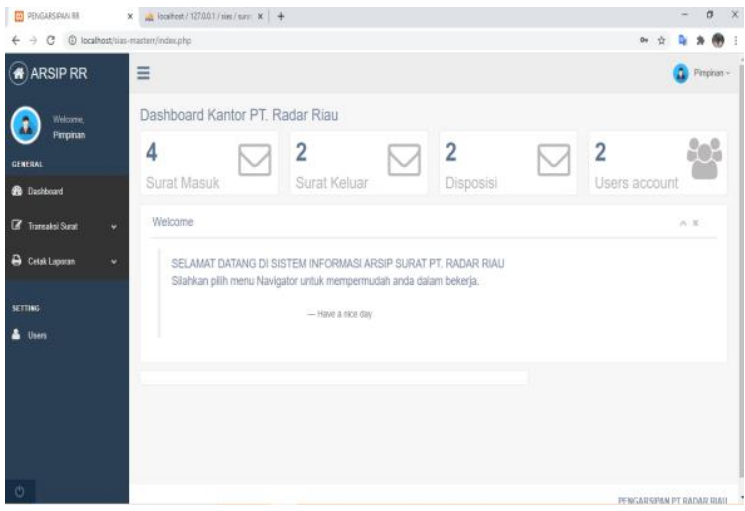

Gambar 4. Halaman Menu Utama

Berdasarkan gambar diatas, dapat dijelaskan bahwa pada halaman utama sistem pengarsipan surat pada PT. Radar Riau terdapat beberapa link menu yaitu Dashboards, Surat Masuk, Surat Keluar, Disposisi dan Cetak Laporan. Di menu Cetak Laporan terdapat submenu yaitu Surat Masuk dan Surat Keluar. Di pojok kanan atas terdapat menu Logout, dan disetiap halaman nantinya menu ini akan terus ada. Halaman utama sebagai halaman sambutan kepada pengunjung sistem, menampilkan kata sambutan ARSIP RR (Sistem Informasi Arsip Surat PT. Radar Riau).

Halaman Input Surat Masuk

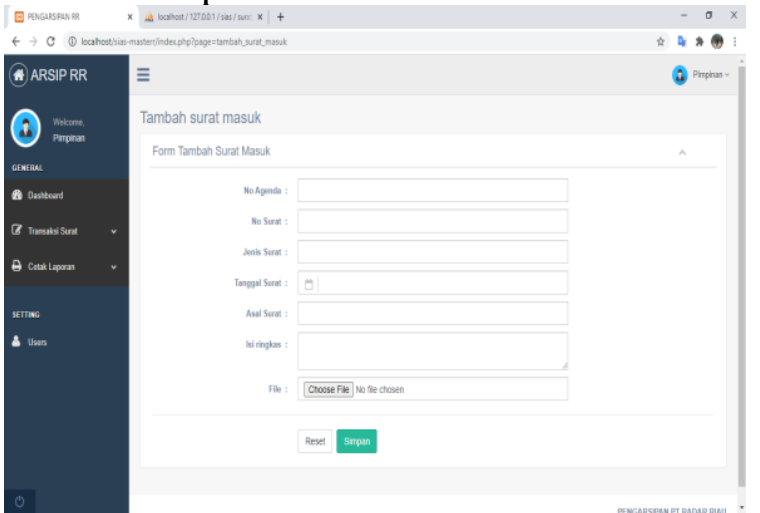

Gambar 5. Halaman Input Surat Masuk

Halaman input surat masuk ini merupakan tampilan form input data surat masuk. Halaman ini berfungsi untuk menambahkan data baru dari Surat Masuk. Dimana didalamnya berisikan nomor surat, alamat pengirim.

Halaman Data Surat Masuk

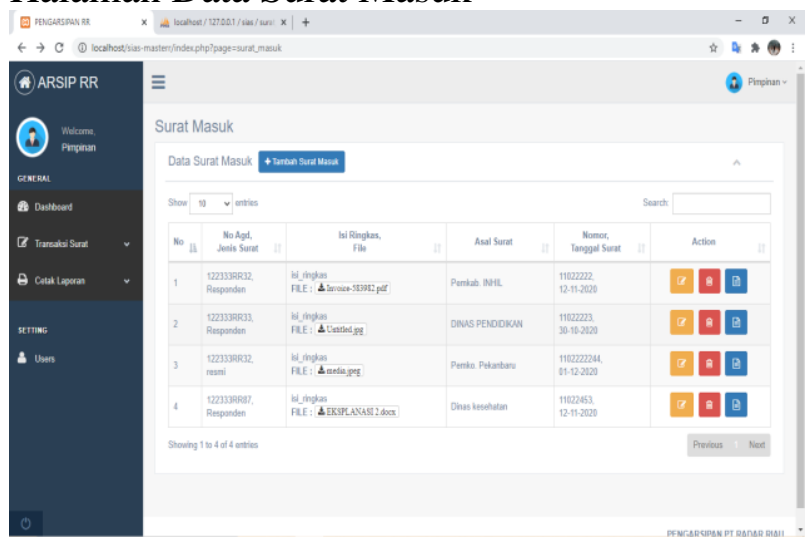

Gambar 6. Halaman Data Surat Masuk

Pada halaman ini user dihadapkan pada tampilan data surat masuk yang telah di inputkan sebelumnya. Pada halaman ini pula admin dapat menambahkan data surat masuk baru, mengedit data surat masuk yang telah di inputkan sebelumnya, menghapus data surat masuk, dan melakukan pencarian terhadap data surat masuk berdasarkan isi data surat, asal surat, atau tanggal surat. 
Halaman Edit Surat Masuk

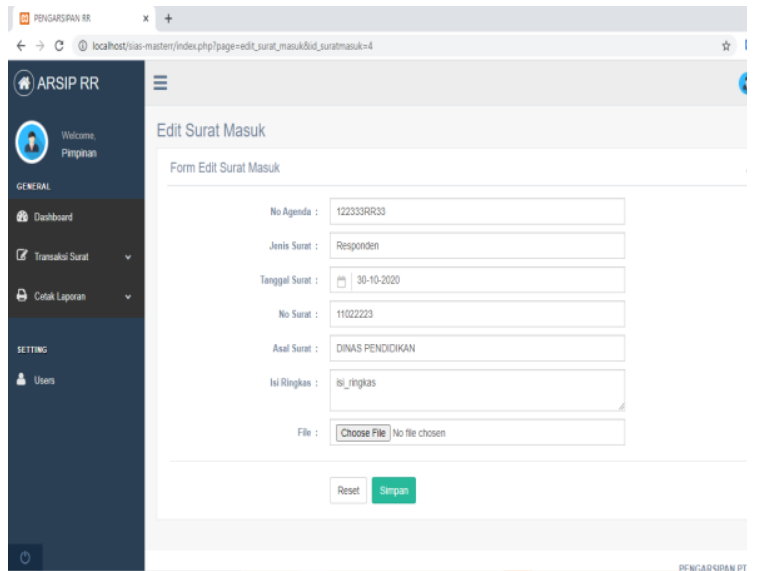

Gambar 7. Halaman Edit Surat Masuk

Halaman edit surat masuk ini merupakan tampilan form edit data surat masuk. Halaman ini berfungsi untuk mengubah data yang sudah ada dari halaman Surat Masuk. Dimana didalamnya berisikan nomor surat, alamat pengirim

Halaman Input Surat Keluar

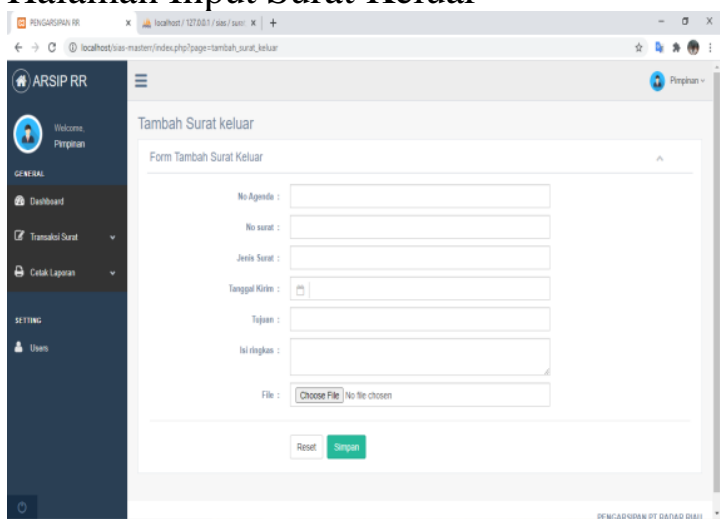

Gambar 8. Halaman Input Surat Keluar

Halaman input surat keluar ini merupakan tampilan form input data surat keluar. Halaman ini berfungsi untuk menambahkan data baru dari surat keluar. Dimana didalamnya berisikan nomor agenda, no surat, jenis surat, tanggal kirim, tujuan, isi ringkas, dan file surat. Lalu simpan untuk menyimpan data surat keluar.
Halaman Data Surat Keluar

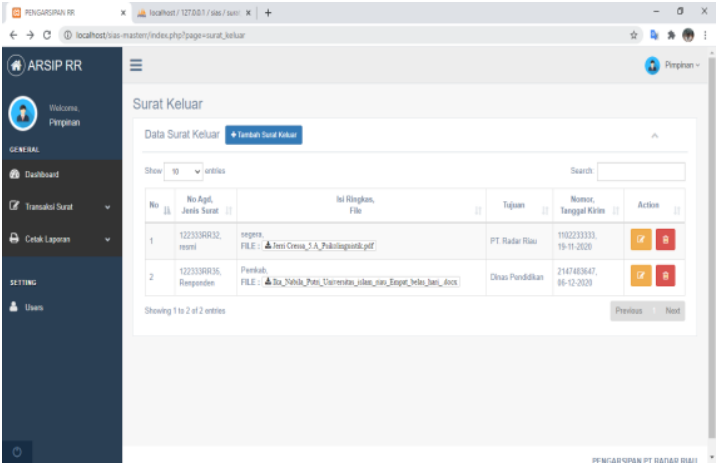

Gambar 9. Halaman Data Surat Keluar

Pada halaman ini user dihadapkan pada tampilan data surat keluar yang telah di inputkan sebelumnya. Pada halaman ini pula user dapat menambahkan data surat keluar yang baru, mengedit data surat keluar yang telah di inputkan sebelumnya, menghapus data surat keluar, dan melakukan pencarian terhadap data surat keluar berdasarkan isi ringkas surat, tujuan surat, atau tanggal surat.

Halaman Edit Surat Keluar

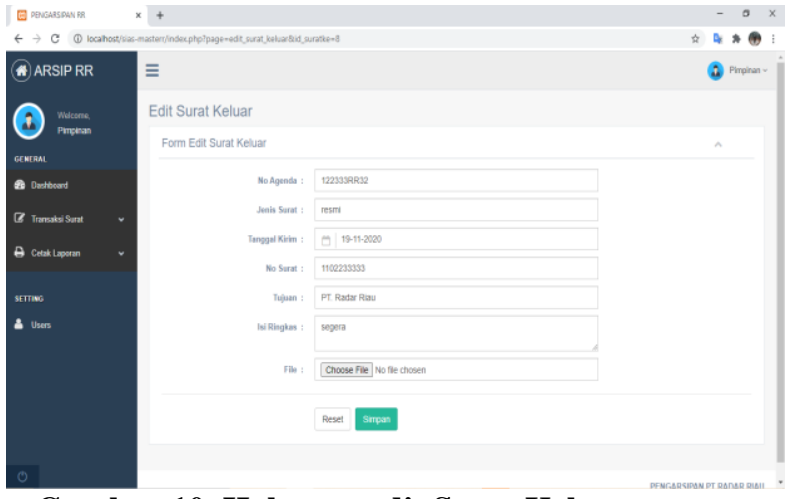

Gambar 10. Halaman edit Surat Keluar

Halaman edit surat keluar ini merupakan tampilan form edit data surat keluar. Halaman ini berfungsi untuk mengubah data yang sudah dari halaman data surat keluar. Dimana didalamnya berisikan nomor agenda, no surat, jenis surat, tanggal kirim, tujuan, isi ringkas, dan file surat. Lalu simpan untuk menyimpan data surat keluar. 
Halaman Input Disposisi Surat

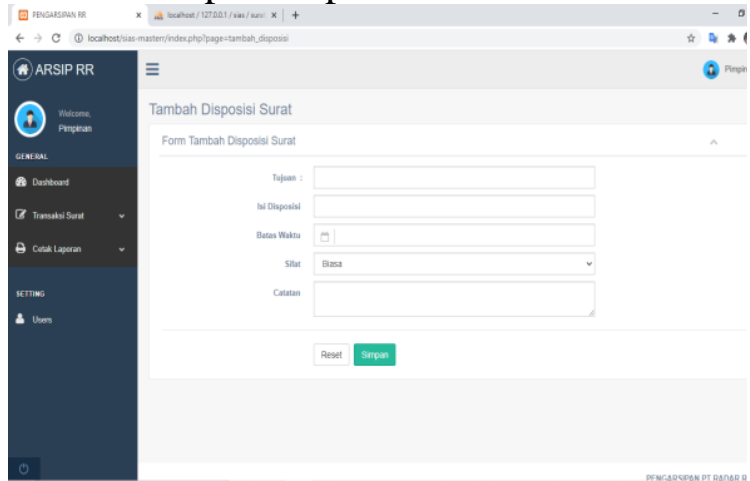

Gambar 11. Halaman Input Disposisi Surat

Halaman input disposisi surat ini merupakan tampilan form input data disposisi surat. Halaman ini berfungsi untuk manambahkan data baru dari disposisi surat. Dimana didalamnya berisikan nomor disposisi, tujuan, isi disposisi, batas waktu, sifat,dan catatan. Lalu simpan untuk menyimpan data disposisi surat.

Halaman Data Disposisi Surat

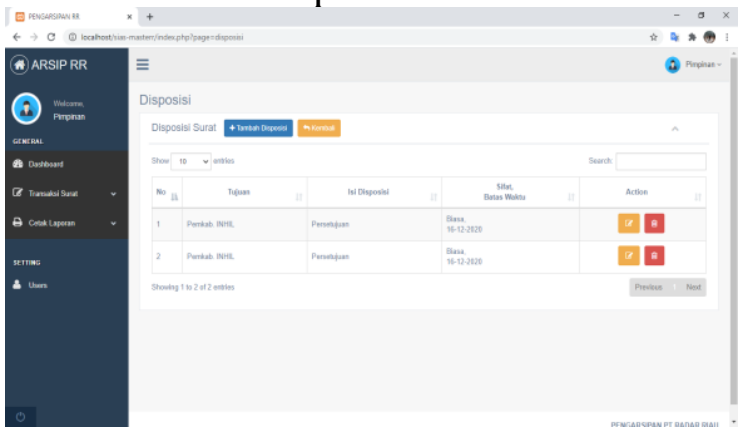

Gambar 12. Halaman Data Disposisi Surat

Pada halaman ini user dihadapkan pada tampilan data disposisi surat yang telah di inputkan sebelumnya. Pada halaman ini pula user dapat menambahkan data disposisi surat yang baru, mengedit data disposisi surat yang telah di inputkan sebelumnya, menghapus data disposisi surat, dan melakukan pencarian terhadap data disposisi surat berdasarkan isi ringkas disposisi, nomor disposisi, atau tanggal disposisi surat.
Halaman Edit Disposisi Surat

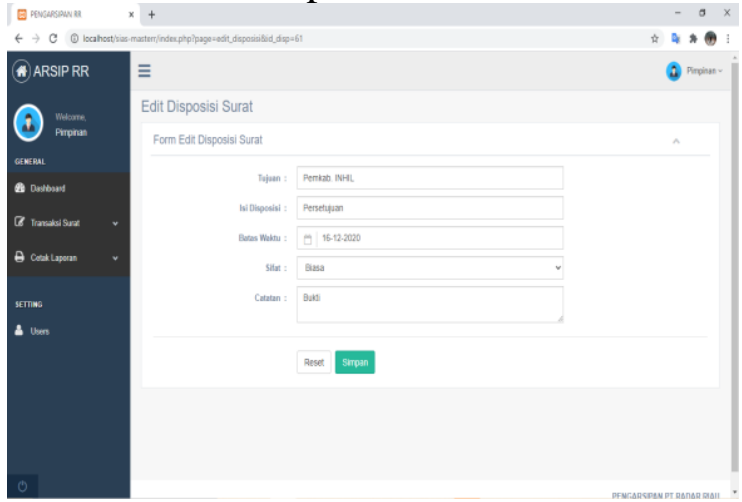

Gambar 13. Halaman edit Disposisi Surat

Halaman Edit disposisi surat ini merupakan tampilan form edit data disposisi surat. Halaman ini berfungsi untuk mengubah data yang sudah ada dari disposisi surat. Dimana didalamnya berisikan nomor disposisi, tujuan, isi disposisi, batas waktu, sifat,dan catatan. Lalu simpan untuk menyimpan data disposisi surat.

\section{Halaman Tampilan Profile}

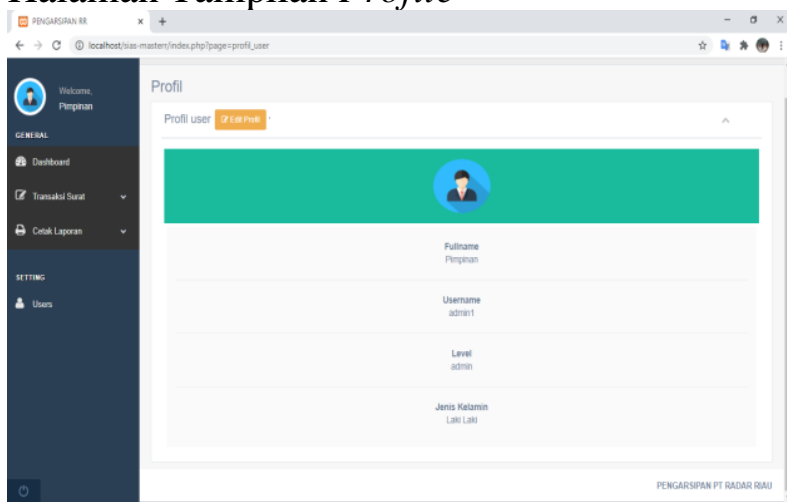

Gambar 14. Halaman Tampilan Profile

Pada Halaman tampilan profile ini merupakan tampilan Form pada data User yang telah Log-in sebelum nya. Halaman ini berfungsi untuk menampilkan data Profile user yang mana di dalam form ini dapat menampilkan data Nama lengkap, Username, level dan Jenis kelamin. 
Halaman Input Users

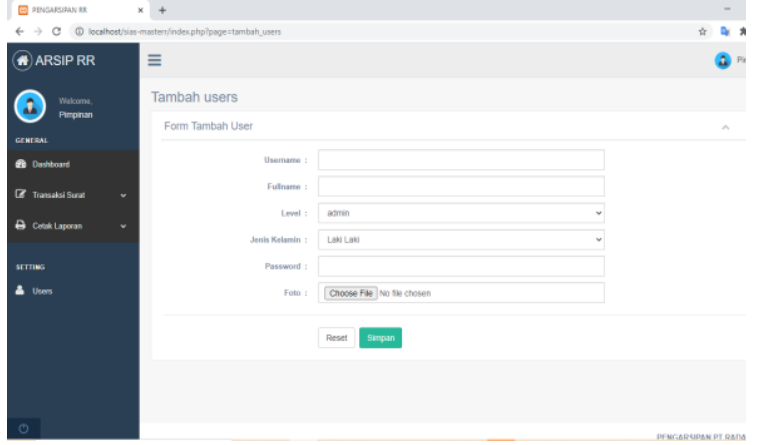

Gambar 15. Halaman Input Users

Halaman input User ini merupakan tampilan form input User. Halaman ini berfungsi untuk manambahkan data User baru. Dimana didalamnya berisikan Username, nama lengkap, level, password dan jenis kelamin, user juga dapat langsung menginput Foto Profile.

\section{Halaman Data Users}

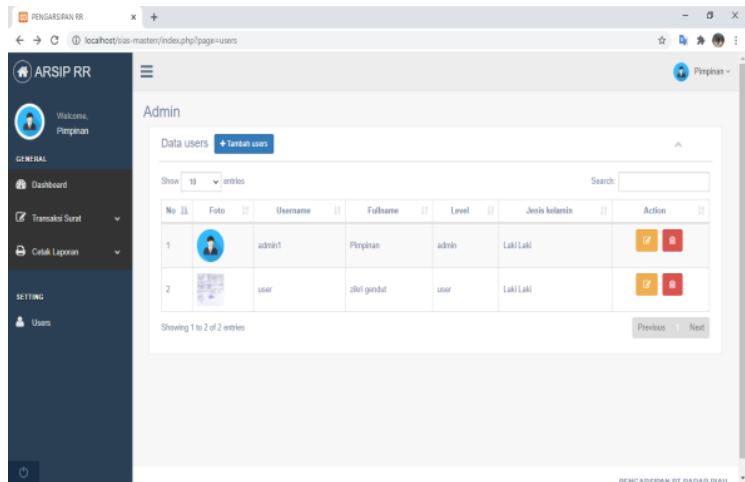

Gambar 16. Halaman Data Users

Pada halaman ini user dihadapkan pada tampilan data Users yang sebelumnya sudah di input. Pada halaman ini pula user dapat menambahkan Users baru dan mengedit atau Menghapus data User yang telah di Input.
Halaman Edit User

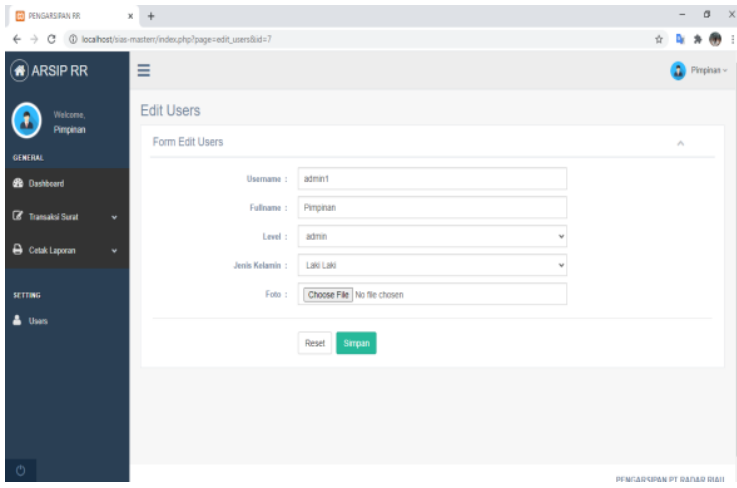

Gambar 17. Halaman Edit User

Halaman Edit User ini merupakan tampilan form edit User. Halaman ini berfungsi untuk mengubah data yang sudah ada dari halaman data user. Dimana didalamnya berisikan Username, nama lengkap, level dan jenis kelamin serta user juga dapat langsung mengubah tampilan foto Profile.

\section{Halaman Cetak Laporan}

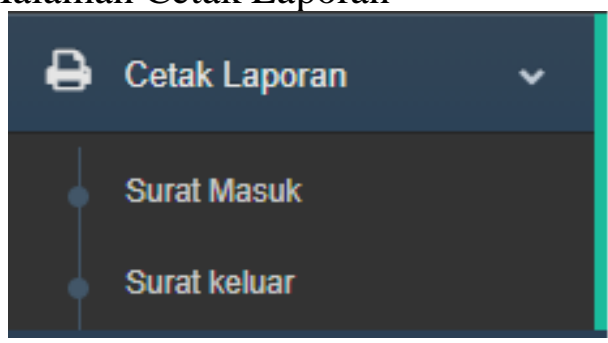

Gambar 18. Halaman Data Disposisi Surat

Pada halaman ini user dihadapkan pada tampilan cetak laporan, dimana user dapat mencetak laporan surat masuk dan laporan surat keluar dalam bentuk file pdf.

Halaman Cetak Laporan surat masuk

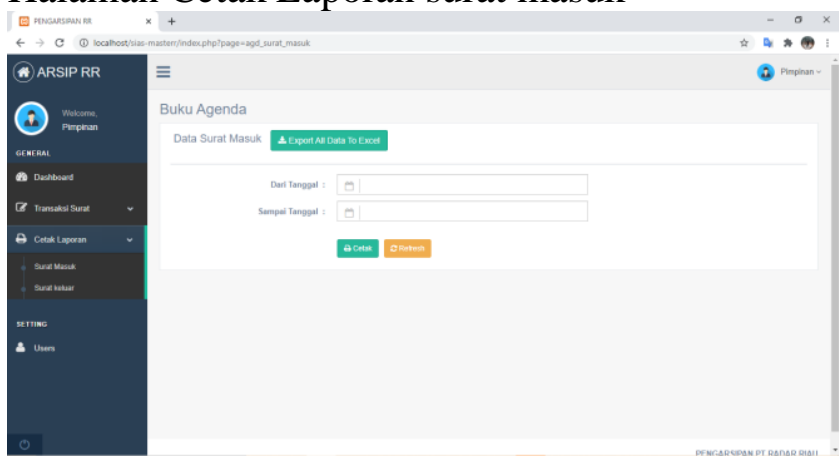

Gambar 19. Halaman Tanggal Cetak Laporan 


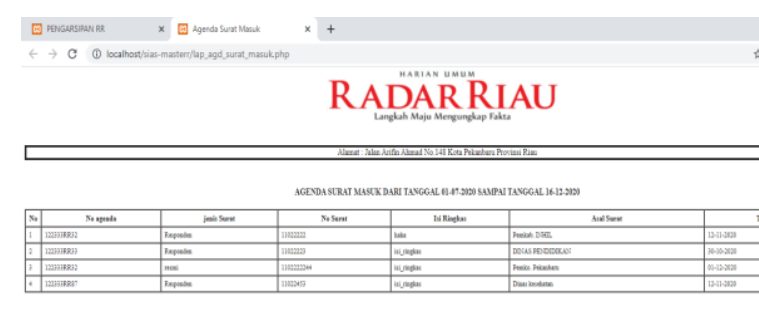

Gambar 20. Halaman Cetak Laporan Surat Masuk

Pada halaman ini user dihadapkan pada tampilan cetak laporan surat masuk, dimana user dapat mencetak laporan surat masuk dalam bentuk file pdf.

Halaman Cetak Laporan Surat Keluar

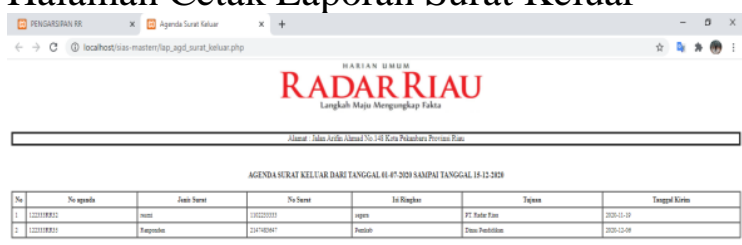

Gambar 21. Halaman Cetak Laporan Surat Keluar

Pada halaman ini user dihadapkan pada tampilan cetak laporan surat keluar, dimana user dapat mencetak laporan surat masuk dalam bentuk file pdf.

\section{SIMPULAN}

Sistem Informasi Pengarsipan dapat membantu staff dalam mengelola data-data surat yang ada pada PT. Radar Riau dengan waktu yang lebih cepat dan juga dapat meminimalisir tingkat kesalahan dalam mengarsipkan surat dan mengelola masalah-masalah dalam penginputan data. Data dapat dengan mudah diarsipkan dengan aman, terintegrasi dan terorganisasi dengan baik, maka instansi tidak akan mengalami kesulitan mengupdate data- data terbaru

\section{DAFTAR PUSTAKA}

Asyari, M. R. (2021). Sistem Informasi Arsip Surat Menyurat. Jurnal Teknologi Dan Sistem Informasi Bisnis, 3(1), 175-184.

Atmala, A. R., \& Ramadhani, S. (2020). Rancang Bangun Sistem Informasi Surat Menyurat di Kementerian Agama Kabupaten Kampar. Jurnal Intra Tech, 4(1), 27-38.

Farell, G., Saputra, H. K., \& Novid, I. (2018). Rancang bangun sistem informasi pengarsipan surat menyurat (studi kasus fakultas teknik unp). Jurnal Teknologi Informasi dan Pendidikan, 11(2), 55-62.

Hamzah, M.L., Purwati, A.A., Rusilawati, E., \& Hamzah. (2019). Rapid Application Development In Design Of Library Information System In Higher Education. International Journal of Scientific \& Technology Research, 8(11), 153156.

Mayasari, M. S., Andrika, Y., Fitriyani, F., \& Zailun, Z. (2020). Optimalisasi Aplikasi Surat Menyurat Pada PT. BPR Sentral Mitra Sejahtera (SMS) Sungailiat. Simetris: Jurnal Teknik Mesin, Elektro dan Ilmu Komputer, 11(1), 185-196.

Nozomi, I., \& Hamzah, M. (2018). Aplikasi Pengolahan Data Surat Izin Usaha Angkutan Barang pada Kantor Dinas Perhubungan Kabupaten Lima puluh Kota. INTECOMS: Journal of Information Technology and Computer Science, 1(1), 110-118. https://doi.org/https://doi.org/10.3 1539/intecoms.v1i1.167 
Oktaviani, E., \& Noviana, S. (2020). Rancang Bangun Sistem Informasi Untuk Meningkatkan Tata Kelola Administrasi Surat Menyurat. Jurnal Informatika, Teknologi dan Sains, 2(3), 203-207.

Setiawan, H., Sakti, E. R. F., Swastika, W., \& Irawan, P. L. T. (2020). Pengembangan Sistem Informasi Administrasi Surat Menyurat untuk Mendukung Layanan di Desa Karangwidoro. In Seminar Nasional Pengabdian Masyarakat Universitas Ma Chung.

Sihotang, H. T. (2018). Sistem Informasi Pengagendaan Surat Berbasis Web Pada Pengadilan Tinggi Medan. Journal Of Informatic Pelita Nusantara, 3(1).

Susanto, A., Septiani, N. W. P., \& Lestari, M. (2021). Perancangan Sistem Informasi Pengelolaan Surat Masuk Surat Keluar dan SPPD Dikelurahan Jatijajar. Jurnal Riset dan Aplikasi Mahasiswa Informatika (JRAMI), 2(01).

Wisudya, R. Y., \& Putra, W. M. (2020). Sistem Informasi Surat Menyurat Desa Ragatunjung. Jurnal Visualika, 6(2), 175-183. 